\title{
A hospitalidade cuiabana a partir do estudo de caso no estabelecimento comercial - “Chá com Bolo Cuiabano da Tia Fran”, Cuiabá (Mato Grosso/MT, Brasil)
}

\author{
The hospitality in Cuiabá (Mato Grosso, Brazil) based on the case study in a \\ commercial establishment - "Chá com Bolo Cuiabano da Tia Fran"
}

\author{
Luciene Aparecida Catravechi (CATRAVECHI, L. A.) ${ }^{*}$
}

\begin{abstract}
RESUMO - O presente texto tem como objetivo investigar a hospitalidade cuiabana praticada no estabelecimento comercial, também caracterizado como casa de chá ou cafeteria - "Chá com Bolo Cuiabano da Tia Fran", na cidade de Cuiabá, capital do estado de Mato Grosso (Brasil). Para a elaboração desse estudo se utilizou de pesquisa bibliográfica e pesquisa de campo, por meio de entrevistas estruturadas com os proprietários do empreendimento e aplicação de questionários semiabertos aos clientes. Como referencial teórico, foram utilizados conceitos de atmosfera e hospitalidade relacionando-os com o perfil desenvolvido pela empresa. A partir da verificação in loco buscou-se identificar os pratos típicos servidos, a estrutura física do estabelecimento, sua decoração, recepção e assim, observou-se a sua atmosfera e hospitalidade presentes naquele espaço. Percebeu-se que a atmosfera criada para atender o público que frequentava o "Chá com Bolo Cuiabano da Tia Fran" era acolhedora, e, incitando nos clientes o desejo de consumir os seus produtos devido a sua organização e apresentação, bem como a sensação de saborear e experimentar os hábitos alimentares da cultura cuiabana. A pesquisa foi realizada no próprio estabelecimento, sendo a sua divulgação autorizada formalmente pelos proprietários no período de 2017 a 2018.
\end{abstract}

Palavras-chave: Turismo; Hospitalidade; Chá com Bolo Cuiabano; Cuiabá.

ABSTRACT - The present paper aimed to investigate the hospitality in Cuiabá, capital of the Mato Grosso State (Brazil), practiced in a commercial establishment, also characterized as a tea house or cafeteria, called "Chá Com Bolo Cuiabano Da Tia Fran". In order to elaborate this study, it was used bibliographical and field research with structured interviews with the establishment owners and the application of semi-open questionnaires. As a theoretical reference, it was used the concepts of atmosphere and hospitality relate them to the profile developed by the company. From the in loco verification, it was sought to identify the typical food served, the place physical structure, its decoration and reception and then, it was observed the atmosphere and hospitality of that space. It was noticed that the atmosphere created to attend the audience at the "Chá com Bolo Cuiabano da Tia Fran" was welcoming and it incited in the customers the desire to consume their products due to their organization and presentation, as well as the sensation of eating, tasting and having the experience with the habits of this city (Cuiabá) culture. The survey was conducted in the establishment, and its disclosure is formally authorized by the owners from 2017 to 2018 .

Key words: Tourism; Hospitality; Chá com Bolo Cuiabano; Cuiabá.

\footnotetext{
* Formação: Graduação, Mestrado e Doutorado em História pela Universidade Federal de Mato Grosso (UFMT). Graduação em Gestão de Turismo pela Universidade Norte do Paraná - UNOPAR/Londrina. Atividade profissional: Docente do Instituto Federal de Educação, Ciência e Tecnologia do Pará (IFPA, Campus Marabá Rural). Endereço físico para correspondência: Rua Raimundo Pinto de Campos, 11, Novo Horizonte - Núcleo Cidade Nova. CEP: 68502-160 - Marabá/PA - Brasil. E-mail: luciene.castravechi@ifpa.edu.br
} 


\section{INTRODUÇÃO}

A hospitalidade tem como principal fator a interação entre as pessoas por meio da reciprocidade. Ela advém das relações interpessoais e é considerada uma virtude que pode ser observada por meio do encontro de diferentes, ou seja, quando se depara com o outro, o "estrangeiro", o estranho. Essa relação ocorre basicamente entre o hóspede e o anfitrião, estabelecendo assim os vínculos sociais que envolvem tanto a intimidade como a etiqueta.

De acordo com Luiz Camargo (2015, p. 48), a hospitalidade íntima é caracterizada pela busca da aproximação, afetividade e expressão de sentimentos, já a hospitalidade pela etiqueta sugere a distância, a polidez, podendo também ser intitulada de hospitalidade neutra. De modo geral, a hospitalidade se constitui no ato de recepcionar pessoas, hospedar, alimentar e agradar.

Nota-se que a hospitalidade abarca diversas questões e comportamentos sociais, bem como pode ser associada à prestação de serviços. Sob esta ótica, Luciema de Boer e Mirian Rejowski (2016) demonstraram que qualquer pessoa fora do seu domicílio, pode ser considerada um hóspede nos locais que frequenta e consome serviços. Assim, também afirmam que "em um restaurante comercial, os clientes consomem, além da comida, da bebida e dos serviços, outros elementos, tais como o ambiente e sua decoração, a atmosfera que dele emana, o entretenimento oferecido e as relações entre os convivas, e destes com os que os atendem" (BOER; REJOWSKI, 2016, p. 7).

Para Boer e Rejowski (2016), a atmosfera pode ser caracterizada como o tom ou estado de espírito difundido pelo espaço, sendo este composto pela decoração interior, refeição festiva e pelo atendimento, os quais implicam em criar uma experiência de socialização a partir da interpretação produzida pelos visitantes. Diante das pesquisas em um restaurante italiano realizadas pelas autoras citadas, verificou-se a proximidade do tema de estudo e interesse de investigar a hospitalidade em um estabelecimento comercial de alimentação, tendo como caso de análise o empreendimento "Chá com Bolo Cuiabano da Tia Fran".

Diante deste cenário, questionou-se: Como a hospitalidade cuiabana estaria presente no empreendimento comercial "Chá com Bolo Cuiabano da Tia Fran”? 
Sob essa problemática formulou-se os seguintes objetivos: investigar a hospitalidade cuiabana praticada no estabelecimento comercial, também caracterizado como casa de chá ou cafeteria - "Chá com Bolo Cuiabano da Tia Fran", na cidade de Cuiabá, capital do estado de Mato Grosso (Brasil); contextualizar a história da alimentação no Brasil e o turismo cultural; descrever o histórico de criação do estabelecimento comercial e analisar a hospitalidade cuiabana a partir da atmosfera propagada pelo empreendimento comercial.

Buscou-se explorar as relações de hospitalidade no que diz respeito ao atendimento, recepção dos consumidores, estrutura do espaço e os alimentos típicos comercializados pelo empreendimento. Muitos quitutes cuiabanos estavam dispostos para apreciação dos clientes, sendo importante destacar que de acordo com Maria Inês Rauter Mancuso et al.( 2017, p. 2) a palavra quitute é de origem angolana e foi trazida pelos africanos escravizados. Quitute, pequena porção de comida, iguaria delicada, significa também carícia, mimo, delicadeza. Os quitutes trazem consigo, heranças culturais dos portugueses e indígenas. A sua confecção, geralmente é realizada por mulheres, sobretudo no presente estudo por meio das receitas herdadas pela proprietária do estabelecimento em análise.

Em relação à confecção de doces e receitas perpetuadas por famílias e suas diferentes gerações, Gilberto Freyre (2007, p. 32) demonstra que:

\footnotetext{
Através das receitas - algumas delas segredos de família -, é uma arte que resiste a seu modo ao tempo, repetindo-se ou recriando-se, com a constância das suas excelências e até de suas sutilezas de sabor; afirmando-se por essa repetição ou por essa recriação. Numa velha receita de doce ou de bolo há uma vida, uma constância, uma capacidade de vir vencendo o tempo sem vir transigindo com as modas nem capitulando, senão em pormenores, ante as inovações, que faltam às receitas de outros gêneros. Às receitas médicas, por exemplo. Uma receita médica de há um século é quase sempre um arcaísmo. Uma receita de bolo do tempo do padre Lopes Gama ou de doce dos dias de Machado de Assis que se tenha tornado um bolo ou um doce clássico - como o sequilho do padre ou o doce de coco do romancista - continua atual, moderna, em dia com o paladar, se não humano, brasileiro.
}

Ao saborear as iguarias da culinária cuiabana, verificou-se que o cliente que adentrava no espaço do "Chá com Bolo Cuiabano da Tia Fran”, estava tendo uma prova da arte que resiste ao tempo, conforme descrita por Freyre (2007), pois as receitas eram provenientes de uma herança marcada por práticas cotidianas de uma família cuiabana, que estava empregando nos seus alimentos um tom da atualidade e modernidade, em 
diálogo com o paladar inspirado pela história e cultura cuiabana, assinaladas pela hospitalidade.

O artigo possui a seguinte estruturação: Introdução; A história da alimentação no Brasil; Histórico do turismo e turismo cultural; O local de estudo e metodologia; Chá com bolo cuiabano da tia Fran: análise da sua atmosfera e hospitalidade; A hospitalidade sob a percepção dos clientes; e as Considerações finais.

Para a compreensão do objeto de estudo fez-se necessário expor a história da alimentação no Brasil e suas influências com as culturas indígenas, portuguesas e africanas, como as principais inspirações para a constituição da culinária brasileira. $\mathrm{O}$ entendimento do turismo gastronômico também foi essencial na compreensão desta segmentação, que conecta o turismo e a cultura de determinada região por meio das suas iguarias gastronômicas. A análise da atmosfera e da hospitalidade no estabelecimento comercial foi verificada pela visita in loco, entrevistas, questionários e fotografias que foram expostas, descritas e analisadas nesta pesquisa.

\section{A HISTÓRIA DA ALIMENTAÇÃO NO BRASIL}

A gastronomia brasileira é influenciada pela cultura dos povos indígenas, africanos e portugueses. Dessa mistura de diferentes culturas e etnias se originou a diversidade dos alimentos presentes na alimentação dos brasileiros. De acordo com Luís da Câmara Cascudo (1967), o paladar brasileiro se deu por meio da junção entre os gêneros locais comestíveis e os hábitos alimentares inspirados de diferentes etnias, impulsionando a fusão dos usos e costumes e assim originando uma sociedade mestiça. O autor ainda demonstra que o preparo dos alimentos até a sua degustação é visto como meio de integração social.

Cascudo (1967) afirma que os alimentos herdados da cultura indígena são: a mandioca, o inhame, o palmito, o milho, o amendoim, o feijão, a banana, as pimentas e as frutas como o caju, o abacaxi, a goiaba, o maracujá, o cajá e o mamão. Da culinária africana, agregou-se o uso do leite de coco e das pimentas, e dos portugueses: a galinha, o ovo, a vaca, o porco, o arroz, a alface, a cana de açúcar, o sal, a couve, o trigo, a 
salsinha, o coentro, a cebolinha, a hortelã e frutas como a maçã, a uva, o limão, a pera e o pêssego.

A variedade de alimentos oriunda das diferentes etnias presentes no Brasil, também foi responsável pelo emprego de diversas técnicas na preparação das comidas. Assim, dos povos indígenas teve-se a influência da farinha da mandioca, o beiju, o pirão, a paçoca, o caruru e a moqueca. Dos africanos herdou-se o cuscuz que passou a ser feito de milho; já dos portugueses, as técnicas de secar a carne, cozinhar os vegetais e fritar os alimentos. Desses vários tipos de ingredientes e técnicas de preparo, conforme Cascudo (1967) se originaram alguns pratos nacionais, como a feijoada, o sarapatel e o vatapá.

No estado de Mato Grosso, especialmente na cidade de Cuiabá pode-se observar a presença multicultural desses alimentos oriunda dos povos indígenas, africanos e portugueses. Desse modo, a gastronomia cuiabana é representada por pratos derivados da flora e fauna nativa, bem como da junção de ingredientes como o frango, a mandioca, a manga, o caju, o charque, os peixes frescos ou secos, com o uso do seu fruto nativo - o pequi e tendo como base das receitas, o arroz.

Constatou-se em Cuiabá uma prática alimentar muito comum, conhecida como o “Chá com Bolo Cuiabano” ou no linguajar local - "Tchá co bolo”, constituído por uma espécie de café da manhã ou chá da tarde, em que se serve basicamente o bolo de arroz ${ }^{1}$, bolo de queijo (frito ou assado), infusão de capim cidreira, chá mate e café. Entretanto, verificou-se que o prato que mais estava representando a baixada cuiabana ${ }^{2}$ era o bolo de arroz, que leva na sua receita o arroz, a mandioca, o açúcar, a manteiga, o coco ralado e a erva doce. Cascudo (1967) demonstra em sua pesquisa que o arroz e o milho substituíram o trigo das receitas portuguesas devido a sua escassez no Brasil. Desse modo, o bolo de arroz constituído essencialmente pelo arroz e a mandioca, demarca

\footnotetext{
${ }^{1}$ Apesar de ser uma iguaria mais recorrente na gastronomia da Baixada Cuiabana, em 19 de janeiro de 2017 o Bolo de Arroz foi declarado pelo Governo do Estado como prato típico do estado de Mato Grosso. Disponível em: <http://g1.globo.com/mato-grosso/noticia/2017/01/lei-declara-o-bolo-de-arroz-cuiabanocomo-prato-tipico-de-mato-grosso.html >. Acesso em: 10/07/2017.

${ }^{2}$ A microrregião da Baixada Cuiabana está localizada na região Centro Sul do estado de Mato Grosso, com extensão territorial de $80.330,31 \mathrm{~km}^{2}$, e é composta por quatorze municípios: Acorizal, Barão de Melgaço, Campo Verde, Chapada dos Guimarães, Cuiabá, Jangada, Nobres, Nossa Senhora do Livramento, Nova Brasilândia, Planalto da Serra, Poconé, Rosário Oeste, Santo Antônio do Leverger e Várzea Grande. Disponível em: <http://sit.mda.gov.br/download/caderno/caderno territorial_016_Baixada\%20Cuiabana\%20\%20MT.pdf>. Acesso em: 26/12/2018.
} 
provavelmente a criação de uma comida que teve que se adequar aos ingredientes presentes e cultiváveis na região mato-grossense.

De acordo com Maria Inês Rauter Mancuso et al. (2017) é provável que o arroz cultivado em Mato Grosso tenha chegado por intermédio das Bandeiras e Monções, no século XVIII. Os Bandeirantes tinham como prática deixar roças pelos caminhos que percorriam, porém o cultivo do arroz necessita de maior atenção, assim a sua produção foi efetivada possivelmente no final do século XVIII por meio dos grupos sociais que se estabeleceram nas fronteiras para a defesa da área. Anteriormente, se utilizavam as espécies silvestres presentes no Pantanal mato-grossense e na Amazônia.

Diante das considerações aqui expostas, percebeu-se que a culinária brasileira é muito atrativa devido a sua diversidade de ingredientes mesclados das culturas dos povos indígenas, africanos e portugueses, que se adequou e substituiu produtos, criando assim novas receitas e brasilidade na elaboração dos seus pratos.

\section{HISTÓRICO DO TURISMO E TURISMO CULTURAL}

O fenômeno turístico tem o seu início no final do século XIX a partir da Segunda Revolução Industrial, e, consequentemente pelo advento dos meios de transportes: navio e trem a vapor que viabilizaram o deslocamento em massa por maiores distâncias e por menos tempo. Esse fato histórico também provocou a divisão do tempo - o tempo biológico e o tempo de trabalho - provocando uma mudança de mentalidade pautada no tempo livre e assim, sobre as viagens turísticas (IGNARRA, 2003).

De acordo com Luiz Renato Ignarra (2003), entre as duas grandes guerras (19191938), cresceu o interesse no turismo como matéria de pesquisa nas universidades, principalmente sob o viés econômico. Nesse sentindo, e conforme o autor aqui citado surgiu a Escola de Berlim que procurou sistematizar o conhecimento das atividades turísticas, através da utilização de pesquisa respaldada por métodos científicos adotados pelas ciências da sociedade à época.

Rodrigo Tadini e Tania Melquiades (2010) afirmam que o período entre guerras possibilitou uma nova realidade para grande parte dos europeus como o advento das 
férias remuneradas, tal fato permitiu que outras classes sociais começassem a viajar, e, concomitantemente surgiu o interesse de uma parcela da população por uma viagem de férias.

Após a Segunda Guerra Mundial, o turismo ganhou novas configurações e melhor organização com o advento da melhoria dos transportes, equipamentos de hospedagem, das agências de viagens, infraestrutura e outros (TADINI; MELQUIADES, 2010).

No Brasil, a partir da década de 1940 inauguraram-se vários hotéis-cassinos, que além dos jogos ofereciam espetáculos nacionais e internacionais, reuniões e festas com pessoas oriundas do país e do exterior. Sendo importante destacar os principais hotéis provenientes daquele período: Parque Balneário Hotel e Atlântico Hotel, em Santos-SP, Quitandinha, em Petrópolis-RJ, Grande Hotel Araxá, em Araxá-MG, Grande Hotel Campos do Jordão, em Campos do Jordão-SP (MATIAS, 2001).

O turismo é uma atividade econômica com várias complexidades, e conforme a Organização Mundial do Turismo - OMT, a sua definição é vista como "Movimento de pessoas a lugar diverso do qual habite por tempo inferior a 360 dias, desde que esta não realize atividades econômicas" (OMT, 2001³ apud BRASIL, 2010, p. 20). Nesta perspectiva, o turismo ocorre por meio de viagens para um local diferente da sua moradia, seja este por lazer, férias, visita a parentes e amigos, motivos profissionais, tratamento de saúde e dentre outros.

Entre os diversos motivos que impulsionam os turistas em viajar, a gastronomia também pode ser um produto ou até mesmo um atrativo de determinada região, pois saborear as comidas típicas também consiste em conhecer o patrimônio cultural de uma localidade. Dessa forma, vivenciar as iguarias gastronômicas implica em conectar o turismo e a cultura, já que o patrimônio tanto material quanto imaterial é primordial para o turismo como um potencial e meio de atração para destinos em específico.

O turismo cultural por meio do patrimônio cultural de determinada localidade vem sendo utilizado como um elo que dá acesso à cultura, história e os hábitos de uma comunidade. Desse modo, o patrimônio cultural é um importante estímulo para a economia do turismo, injetando muitas receitas e grande volume de investimentos. Portanto, conforme Margarita Barretto (2000, p. 19): “entende-se por turismo cultural

\footnotetext{
${ }^{3}$ OMT, Organização Mundial do Turismo. Introdução ao Turismo. São Paulo: Roca, 2001.
} 
todo o turismo em que o principal atrativo não seja a natureza, mas algum aspecto da cultura humana".

A gastronomia como expressão cultural de determinada comunidade é importante e relevante para o turismo, pois movimenta a economia local e cria inúmeras oportunidades para esse nicho de mercado. A comida típica provoca nos turistas diversas sensações que envolvem o sabor e a arte de se alimentar, bem como a aproximação com a identidade e história de uma localidade. Nesse sentido, Ignarra (2003) demonstra que a gastronomia típica é de suma importância para os turistas, tendo em vista que estes se deslocam até os estabelecimentos e restaurantes que expressam a cozinha tradicional local. Deste modo, os restaurantes típicos devem se adequar para atender os clientes sem se desfazer dos seus atributos essenciais, conforme se exporá mais adiante em relação ao estabelecimento "Chá com Bolo Cuiabano da Tia Fran".

\section{O LOCAL DE ESTUDO E METODOLOGIA}

De acordo com o Instituto de Planejamento e Desenvolvimento Urbano - IPDU (2010), o município de Cuiabá possui uma área de $3.538,17 \mathrm{~km}^{2}$. Integram-se ao município, os Distritos Coxipó da Ponte, Coxipó do Ouro e Nossa Senhora da Guia. Cuiabá localiza-se na mesorregião centro-sul mato-grossense, na microrregião Cuiabá. A sede municipal, situada à altitude de 177 metros, segundo demarcação realizada pela Comissão Rondon em 1909, encontrando-se no Centro Geodésico da América do Sul, nas coordenadas geográficas $15^{\circ} 35^{\prime} 56^{\prime}$ ' de latitude sul (S) e $56^{\circ} 06^{\prime} 55^{\prime}$ ' de longitude oeste (W) de Greenwich (Gr) (CAMARACBA, s.d.).

A presente pesquisa possui caráter exploratório, pois de acordo com Antonio Carlos Gil (2008), esta classificação proporciona maior proximidade com o problema, ou seja, a sua explicitação. Os procedimentos metodológicos utilizados para atingir os objetivos propostos neste estudo incluíram análises de notícias de jornais, revistas e sites. Foram realizadas pesquisas a campo até o estabelecimento "Chá com Bolo Cuiabano da Tia Fran", onde se realizou uma entrevista semiestruturada com os proprietários do comércio e a aplicação de questionários aos clientes do estabelecimento. O uso de questionários é definido por Gil (1999, p. 128): 
[...] como a técnica de investigação composta por um número mais ou menos elevado de questões apresentadas por escrito às pessoas, tendo por objetivo o conhecimento de opiniões, crenças, sentimentos, interesses, expectativas, situações vivenciadas etc.

Foram aplicados aos clientes do estabelecimento comercial 10 questionários compostos por 12 perguntas, sendo 7 de múltipla escolha e 5 questões abertas. Este tipo de investigação não se resumiu a fazer perguntas e descrever respostas, mas empregou técnicas específicas que se adequaram às normas gerais da pesquisa. O questionário estruturado continha perguntas abertas e fechadas de forma a identificar a avaliação e o grau de satisfação dos clientes em relação à hospitalidade, decoração, atmosfera e prestação de serviços no estabelecimento "Chá com Bolo da Tia Fran”.

A partir da verificação in loco identificou-se os pratos típicos servidos, a estrutura física do estabelecimento, sua decoração, recepção e assim, observou-se a sua atmosfera e hospitalidade presentes naquele espaço.

Esta investigação também teve como proposta metodológica a análise bibliográfica dos estudos que dialogassem com o tema da pesquisa, pois o turismo possui uma natureza complexa, necessitando de diversos métodos e disciplinas que se interligam para produzir conhecimentos e maior entendimento do fenômeno (MARUJO, 2016, p. 114). Assim, as pesquisas no campo do turismo podem ser compreendidas como um fenômeno econômico, social, histórico, geográfico e cultural, possibilitando a sua análise nos diferentes âmbitos da ciência.

Para a compreensão do objeto de estudo proposto nesta investigação apoiou-se no método do estudo de caso, conforme Noémi Marujo, ao afirmar que "o estudo de caso tem sido utilizado extensivamente na pesquisa em turismo" (MARUJO, 2016, p. 118). De acordo com a autora, o uso do método do estudo de caso está aumentando no campo de investigação em turismo, já que essa metodologia possibilita um melhor entendimento de determinados fenômenos que não poderiam ser analisados por meio de outros métodos.

Neste sentido, Gil (2008) descreve o estudo de caso como um estudo denso e minucioso de um ou poucos objetos, de forma que propicie seu extenso e profundo conhecimento. 
Marujo (2016, p. 121) assinala que o estudo de caso, na investigação turística pode ser sintetizado da seguinte forma:

\begin{abstract}
Capacidade para colocar organizações, pessoas, eventos e experiências no seu contexto social e histórico; o caso único ou um número limitado de casos oferece um conjunto de dados de gestão fácil, sobretudo, quando os recursos são limitados; habilidade para tratar o objeto de estudo como um todo, mais do que abstrair um conjunto limitado de aspectos; os métodos múltiplos triangulação - estão implícitos e constituem um ponto forte; não existe necessidade de generalizar a uma determinada população alargada; a flexibilidade na estratégia da recolha dos dados permite aos investigadores adaptar a sua estratégia de investigação de acordo com o desenvolvimento da pesquisa.
\end{abstract}

O estudo de caso permite uma análise minuciosa do objeto pesquisado, além de proporcionar uma série de dados, bem como entender as características intrínsecas e singulares do caso investigado.

Ao utilizar o estudo de caso buscou-se compreender o fenômeno turístico, seja ele no âmbito do planejamento e desenvolvimento do turismo; nas formas alternativas da experiência turística; na promoção e divulgação do atrativo turístico; e na segmentação do mercado do turismo.

O estudo de caso no estabelecimento "Chá com Bolo da Tia Fran”, possibilitou a compreensão da hospitalidade cuiabana, a qual foi analisada por meio da atmosfera criada pelo empreendimento comercial, conforme discutido no tópico a seguir.

\title{
5 CHÁ COM BOLO CUIABANO DA TIA FRAN: ANÁllSE DA SUA ATMOSFERA E HOSPITALIDADE
}

O estabelecimento "Chá com Bolo da Tia Fran" está localizado na Avenida Senador Metello, 1909, Jardim Independência, Cuiabá/MT. A cafeteria foi fundada no ano de 2007 pelos proprietários, Jackson Silva e Francisca Silva (Tia Fran). A ideia de abrir o negócio surgiu a partir de um problema de saúde que o senhor Jackson desenvolveu, assim questionado por sua psicóloga, esta lhe perguntou o que a sua 
esposa sabia fazer, e então, o casal resolveu deixar os seus empregos e se dedicar a venda do bolo de arroz aos domingos de "porta em porta"

Com o aumento da procura dos seus produtos, as pessoas passaram a ir até a residência do casal para comprar os seus quitutes, e também solicitar o café como acompanhamento dos bolos. Desse modo, os proprietários resolveram servir o Chá com Bolo Cuiabano nas dependências da sua casa com apenas quatros jogos de cadeiras, mas o negócio cresceu de forma extraordinária e o comércio teve que ser mudado para uma casa maior em que se acomodaram quarenta jogos de mesas, tendo a média de 800 salgados vendidos aos domingos ${ }^{5}$.

Conforme os relatos de Jackson Silva, as receitas dos quitutes, especialmente do bolo de queijo e do bolo de arroz foram herdadas do pai de Francisca Silva (Tia Fran). Com a dedicação ao negócio e a interação com os clientes, a saúde de Jackson Silva teve uma melhora de $70 \%$, pois este passou a visualizar sua atividade de receber as pessoas na sua casa como uma terapia. Assim, chegou-se à conclusão que a hospitalidade do "Chá com Bolo Cuiabano da Tia Fran", advém dessa relação familiar e da busca por qualidade de vida através da recepção calorosa desse casal de cuiabanos.

Ao adentrar no espaço do "Chá com Bolo da Tia Fran", se deparou com um ambiente acolhedor e especialmente receptivo, ou seja, tomado por uma atmosfera que envolvia diversas sensações e a ideia de estar partilhando da cultura e história da população cuiabana. Dessa forma, Kotler define atmosfera como "o esforço para projetar ambientes de compra que produzem efeitos emocionais específicos no comprador e que aumente sua probabilidade de compra” (KOTLER $1973^{6}$ apud REGO; SILVA, 2003, p. 121). Nesse sentido, a atmosfera criada no estabelecimento comercial remetia um lugar agradável pensado para trazer conforto e bem-estar aos seus clientes, provocando nestes a confiança de se alimentarem em um local que se considerou expressar organização, e, consequentemente a vontade de consumir os seus produtos.

O "Chá com Bolo da Tia Fran” foi decorado com peças e cores que lembravam a cultura e identidade cuiabana, isto é, um espaço que passou a transmitir uma atmosfera

\footnotetext{
${ }^{4}$ SILVA, Jackson. Entrevista de treze minutos concedida à autora, em 19 de julho de 2017 na cidade de Cuiabá.

${ }^{5}$ Idem.

${ }^{6}$ KOTLER, P. Atmospherics as a Marketing Tool. Journal of Retailing, v. 49 (Winter), p. 48-64, 1973.
} 
cercada pela história e costume dos cuiabanos, dessa forma considerou-se que a ambientação do lugar é algo fundamental, conforme John Mowen e Michael Minor (1998) ${ }^{7}$ apud Raul Rego e Edson Silva (2003, p. 121), pois a:

\begin{abstract}
Atmosfera refere-se a como os administradores manipulam o projeto da construção, o espaço interior, o arranjo das seções, a textura dos carpetes e paredes, cheiro, cores, formas e sons experienciados pelos consumidores tudo para obter um certo efeito.
\end{abstract}

Verificou-se que a decoração exposta no "Chá com Bolo da Tia Fran” estava assinalada por diversos elementos que expressavam a cultura cuiabana, como, por exemplo, o uso dos tecidos de chita com amarrações e fixados na parede; a viola de cocho e o ganzá, que são instrumentos musicais de Cuiabá, estando dispostos para apreciação e possíveis registros fotográficos dos clientes. O ambiente também estava tomado por muitos quadros com pinturas que lembravam o Pantanal, bem como a sua fauna e flora; a mesa onde estavam dispostos o chá e o café estava decorada por objetos do artesanato cuiabano cuja matéria prima é a argila, em que são esculpidos os animais que compõem o bioma da baixada cuiabana, como também a moringa cuiabana, conforme a imagem abaixo:

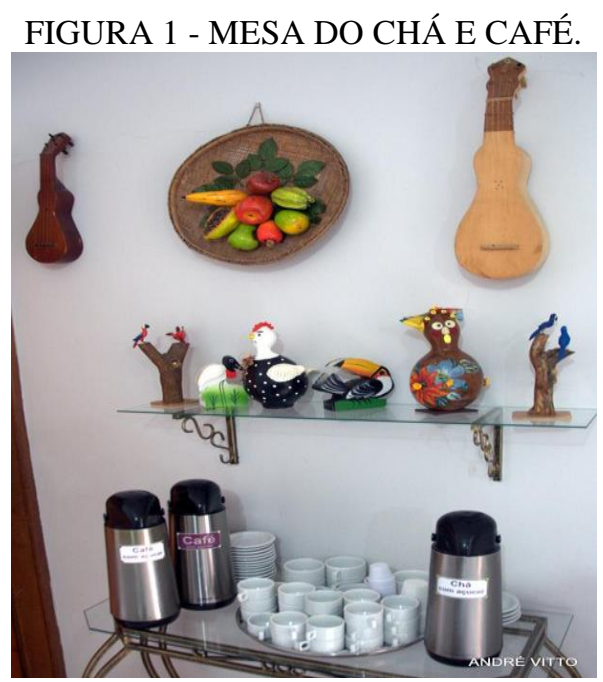

FONTE: Pesquisa de Campo (2017).

Os clientes podiam se acomodar em dois espaços diferentes: um interno onde ficava o balcão de atendimento juntamente com a estufa dos bolos e salgados, conforme

\footnotetext{
${ }^{7}$ MOWEN, J. C.; MINOR; M. S. Comportamento do consumidor. São Paulo: Prentice Hall, 1998.
} 
apresentado na Figura 2. Outro externo em que as mesas e cadeiras ficavam dispersas na varanda em um espaço lateral à residência, no qual as mesas encontravam-se à sombra de um pé de manga, exposto na Figura 3. Todos esses ambientes estavam carregados de uma atmosfera planejada de acordo com Mowen e Minor (1998) ${ }^{8}$ citados por Rego e Silva (2003), em que as seções foram projetadas e decoradas com objetos, cores e sons que lembravam os hábitos cuiabanos, sendo importante destacar que a música ambiente era uma seleção das composições do Rasqueado cuiabano ${ }^{9}$.

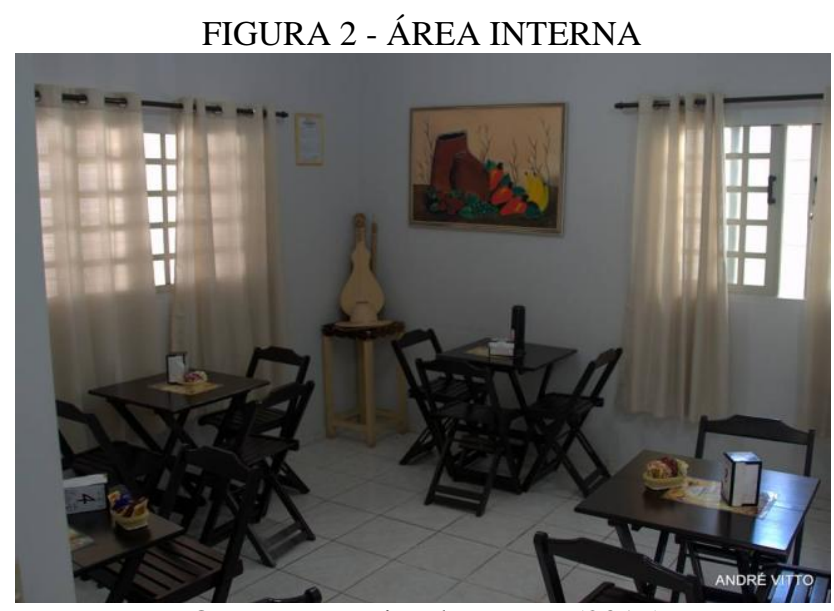

FONTE: Pesquisa de campo (2017).

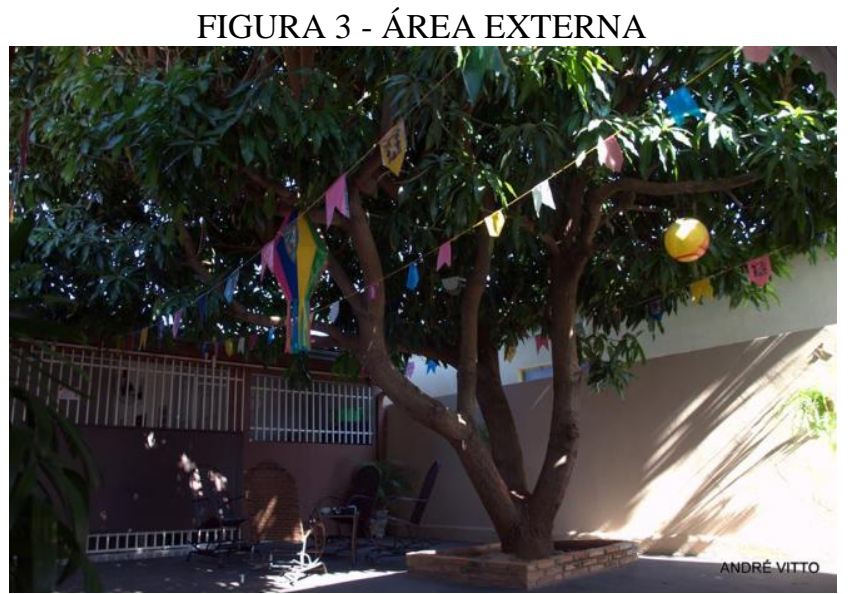

FONTE: Pesquisa de campo (2017).

\footnotetext{
${ }^{8}$ MOWEN, J. C.; MINOR; M. S. Comportamento do consumidor. São Paulo: Prentice Hall, 1998.

${ }^{9}$ O Rasqueado Cuiabano tem origem em fins do século XIX, com influência do período pós-guerra do Paraguai. Os paraguaios remanescentes da Guerra começaram a se integrar junto com os ribeirinhos mato-grossenses para o convívio do dia-a-dia. Nessa interação de simbioses práticas, a viola-de-cocho e o violão paraguaio começaram a tocar uma nova música, mistura de siriri mato-grossense e polca paraguaia. O novo ritmo surgiu para a exaltação da volta à vida e para sepultar as lágrimas do grande conflito que influenciou o rumo da história latino-americana. Disponível em: <http://www.portalmatogrosso.com.br/imprime.php?cid=16950\&sid=358 >. Acesso em: 18/07/2017.
} 
De acordo com Edson Silva (2001), a atmosfera intervém na percepção da qualidade do produto e favorece as vendas. Ao investir na apresentação e elaboração de um espaço que comercializa a gastronomia típica, este obtém vantagem competitiva sob a ótica da atratividade turística, pois a divulgação e desenvolvimento da atmosfera de um lugar ou localidade podem contribuir no crescimento do número de clientes, e, consequentemente de turistas satisfeitos.

A atmosfera, segundo Rego e Silva (2003) também é um fator importante para a hospitalidade, tendo em vista que a atmosfera pode exercer influência significativa sobre a qualidade de uma localidade turística, sendo esta desenvolvida desde a escolha do destino e a sua permanência no local. Desse modo, ainda conforme os autores citados, a atmosfera é responsável por atender as expectativas de um turista em relação ao lugar visitado, pois ela oportuniza as sensações desejadas, como, por exemplo, o sentimento de acolhimento, conforto, satisfação e prazer em conhecer e vivenciar um produto turístico, conforme apresentado e idealizado.

A hospitalidade prestada no "Chá com Bolo Cuiabano da Tia Fran", pôde ser percebida tanto na criação de uma atmosfera preparada para o bem receber ou atender, quanto no que diz respeito na vivência da identidade e cultura cuiabana. De acordo com Raphael Pimentel (2012, p. 57), a hospitalidade transforma estranhos em familiares, bem como exerce a confiança e cordialidade entre anfitriões e visitantes que compartilham de um mesmo espaço, assim, o termo "hospitaleiro" também denota a qualidade de um indivíduo ou local que pratica o bem receber.

Nesse sentido, considerou-se poder caracterizar o "Chá com Bolo Cuiabano da Tia Fran”, como um local em que se estava praticando a hospitalidade e os seus proprietários poderiam ser considerados hospitaleiros, conforme a entrevista de Jackson Silva" : "a hospitalidade é atender bem as pessoas, receber bem [...] pode ser classe baixa, média ou elite que eu trato tudo igual". Quando perguntado se o seu jeito hospitaleiro vinha do fato do mesmo ser cuiabano, ele disse que "sim veio do jeito cuiabano, então eu paro e converso com um e com outro. Quando a pessoa some e eu vejo no portão, eu falo: o que foi que você sumiu?". Durante as visitas a campo, notouse que os clientes foram recebidos de forma cordial e tratados como velhos conhecidos, mesmo estes tendo adentrado o comércio pela primeira vez. Sob essa ótica a

\footnotetext{
${ }^{10}$ SILVA, Jackson. Entrevista de treze minutos concedida à autora, em 19 de julho de 2017 na cidade de Cuiabá.
} 
hospitalidade do "Chá com Bolo Cuiabano da Tia Fran" poderia ser vista como uma partilha de experiências que agregava diversas culturas, identidades e costumes como uma relação de troca de valores e conhecimento entre o visitante e o anfitrião.

Conforme Rego e Silva (2003) existem algumas variáveis que compõem a atmosfera de um ambiente, sendo estas externas e internas. A atmosfera externa é composta pela fachada do local, cores, sinalização e etc.; já a atmosfera interior pode ser percebida pelo consumidor através da decoração, iluminação, cores, sons e outras percepções.

As características que constituem as variáveis da atmosfera foram observadas no espaço do "Chá com Bolo Cuiabano da Tia Fran”, já que a sua fachada estava pintada de marrom, fazendo com que o consumidor se lembrasse de um bolo de arroz bem assado, crocante e saboroso, uma marca de qualidade da cafeteria. Os letreiros com o nome, telefone, horários e dias de atendimento do estabelecimento foram elaborados com um layout cujas letras se mesclavam entre clássicas e modernas, conferindo a impressão de que a designação do local reportava aos antigos cafés e cafeterias, logo a escrita moderna facilitava a leitura das informações do horário e dias de atendimento. Como figuras ilustrativas, usaram elementos que lembravam a cultura cuiabana a partir do emprego das violas de cocho, bem como a reprodução da fauna e flora do Pantanal Mato-grossense, conforme pode ser visualizada na figura 4 exposta a seguir:

FIGURA 4 - FACHADA DO ESTABELECIMENTO COMERCIAL

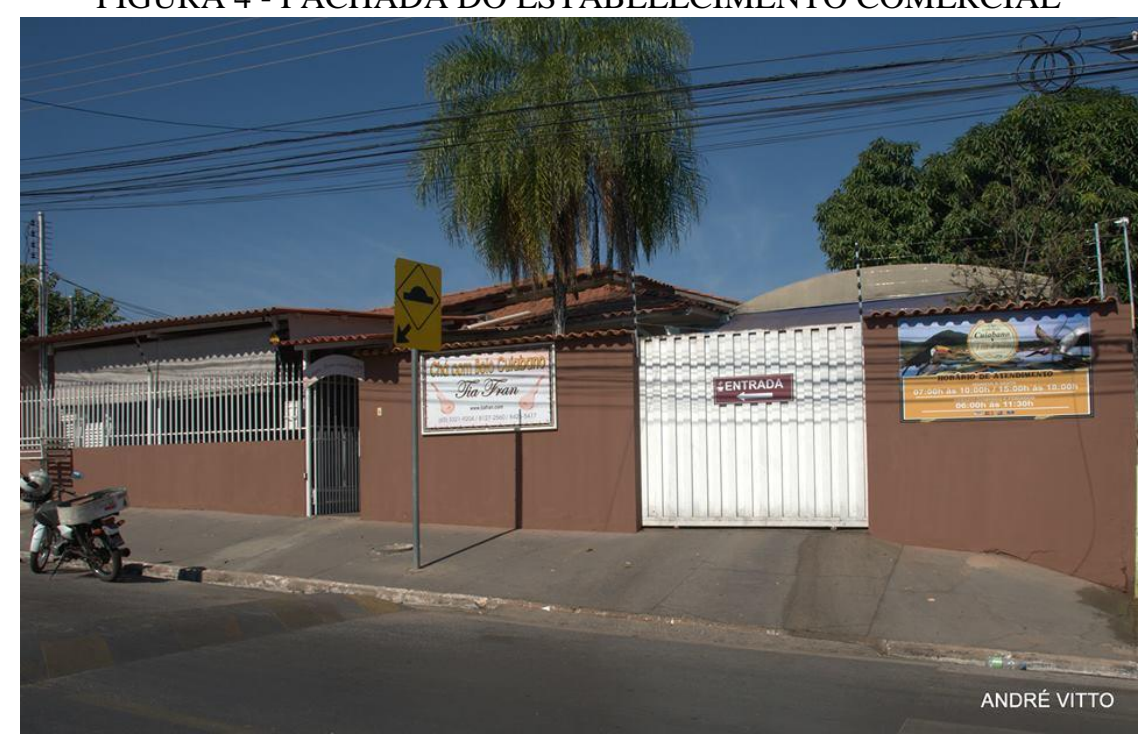

FONTE: Pesquisa de campo (2017). 
Observou-se que o ambiente interno estava marcado por diversos objetos provenientes da cultura cuiabana. Conforme entrevista cedida por Jackson Silva ${ }^{11}$, a decoração foi pensada por ele e muitas peças decorativas foram dadas pelos seus amigos. Segundo o entrevistado: "eu que vou inventando, fui ganhando como aquela máquina de costura a manivela, eu ganhei. Um colega trouxe aquele engenho, e a gente vai inventando e vai dando certo". Ao ser perguntado se a decoração seria importante para a atração dos turistas, o mesmo respondeu que "sim, porque os nossos avós usavam muita chita na casa deles, cortina de chita, então usavam muita chita que é um pano mais barato e é bonito, mas só não pode ver água [risos], porque desbota na hora”.

O cuidado dos proprietários em projetar um ambiente com traços que lembrassem a identidade cuiabana denotou a relação de uma atmosfera acolhedora, e, expressou a percepção de qualidade do produto, bem como tocou o sentido da visão que é percussor da hospitalidade, principalmente se as imagens aguçarem as suas lembranças e atender as expectativas que o turista projetou em relação ao atrativo, conforme descrito por Sinara Campos (2008).

Ao se analisar um empreendimento que envolve os serviços de alimentos e bebidas é importante destacar o paladar como um sentido que se associa com a hospitalidade, como descrito por Campos (2008), pois é a partir da apreciação dos sabores que o turista irá atribuir a qualificação para os alimentos e associá-los com a localidade (cidade) visitada, e, como resultado à sua hospitalidade. Ainda de acordo com Campos (2008), os sentimentos presentes na associação paladar/hospitalidade podem ser vistos por meio da percepção dos gostos e expectativas existentes no ato de provar determinado alimento, e assim, provocar no indivíduo a conexão com lembranças positivas ou não, definindo ser algo hospitaleiro ou desagradável.

Nessa perspectiva, os turistas que conhecerem o "Chá com Bolo Cuiabano da Tia Fran”, poderão integrar-se com a cultura local, principalmente ao provarem o bolo de arroz que é um prato típico da culinária cuiabana. A qualidade do atendimento por seus garçons e funcionários, possibilitará aos visitantes apreciarem a sua hospitalidade também atrelada à preparação dos pratos e à condição em que estes se encontrarem, como um fator que intervém na assimilação da hospitalidade com o paladar.

\footnotetext{
${ }^{11}$ SILVA, Jackson. Entrevista de treze minutos concedida à autora, em 19 de julho de 2017 na cidade de Cuiabá.
} 
O olfato também é um sentido que pode ser relacionado com a hospitalidade, pois através dos estímulos olfativos que os turistas poderão trazer à tona lembranças de momentos bons ou agradáveis, mas é claro que se deve levar em consideração que os odores possuem o seu caráter individual (CAMPOS, 2008). Sob essa ótica, a memória olfativa pode provocar a recordação de determinado lugar visitado ou dos acontecimentos vivenciados.

Os cheiros presentes no "Chá com Bolo Cuiabano da Tia Fran", estavam sendo provenientes principalmente do vapor exalado pela infusão de capim cidreira e do bolo de arroz quentinho saindo do forno para a mesa do cliente. Esses odores são exclusivos da cultura cuiabana, assim os turistas que senti-los poderão associá-los a eventos e lembranças vividas em Cuiabá como um sentimento que indica a hospitalidade da cidade.

A audição também é um indicativo de hospitalidade, segundo Campos (2008). Ao visitar uma cidade, o turista pode ouvir diversos sons relacionados à rotina de um espaço urbano tomado por buzinas, carros, construções etc.; e também sons naturais como pássaros, vento, sotaque das falas das pessoas, entre outros.

Os sons emitidos no "Chá com Bolo Cuiabano da Tia Fran" estavam propagando imprescindivelmente a cultura e identidade cuiabana, haja vista que a música de fundo estava tendo como ritmo o Rasqueado cuiabano, além do sotaque cuiabano, também conhecido como "cuiabanês", presente nas falas dos proprietários, Jackson Silva e Francisca Silva (Tia Fran). Os turistas passavam por uma experiência diferenciada ao ter a sua adição em contato com as músicas e o linguajar cuiabano, assim eles se deparavam com uma atmosfera que interferia na qualidade de um produto e promovia a venda da gastronomia local, bem como permitia aos clientes o contato com costumes e tradições exclusivamente cuiabanas.

Conforme Campos (2008) o tato também é um indicativo de hospitalidade e pode ser exemplificado pelo toque, contato físico, sensação de frio ou calor. Entretanto, o tato e os seus elementos identificadores são os mais complexos de se relacionar com a hospitalidade, devido à diversidade cultural em relação a esse sentido.

No “Chá com Bolo Cuiabano da Tia Fran”, os turistas poderiam vivenciar o tato por meio do cumprimento de aperto de mãos que os seus proprietários expressavam aos seus clientes, bem como experimentar a sensação de tomar uma xícara de infusão de 
capim cidreira na calorosa cidade de Cuiabá, e talvez sofrer um pequeno acidente e queimar a língua nesse processo. A transmissão do calor cuiabano e a recepção do estabelecimento comercial são sensações que os visitantes poderiam levar consigo, e, possivelmente estabeleceriam suas percepções na relação tato/hospitalidade.

O turismo pode agregar os cinco sentidos humanos, como também se relacionar com diversas culturas, conforme relatado por Jackson Silva ${ }^{12}$ que alegou receber turistas de diversos lugares e países, sendo estes franceses, americanos, chilenos e paraguaios que eram trazidos pelos guias de turismo, antes destes se deslocarem para o Pantanal. Para atender a demanda de turistas estrangeiros, o cardápio da cafeteria encontrava-se nas línguas portuguesa e inglesa. Assim, para receber os turistas, Jackson Silva explicou que "pego a viola de cocho, o chapéu de palha e o ganzá, e falo para eles: tirem fotos e eles ficam todos contentes".

A atitude descrita pelo proprietário do "Chá com Bolo Cuiabano da Tia Fran", poderia ser relacionada com Pimentel em que no turismo a hospitalidade ocorre através da espontaneidade e da artificialidade, as quais quando planejadas envolvem estratégias privadas e políticas públicas, onde as localidades com potencial turístico podem ser preparadas para serem hospitaleiras e receptivas. Portanto, assinaladas por uma hospitalidade profissional com o intuito de oferecer estruturas e prestação de serviços com o foco exclusivo ou quase exclusivamente para o atendimento de turistas, ou seja, a criação de uma "hospitalidade turística" (PIMENTEL, 2012, p. 57-58).

Entretanto, a hospitalidade do "Chá com Bolo Cuiabano da Tia Fran" poderia ser considerada de forma espontânea, pois o estabelecimento comercial não seria um propagador do "não-lugar" ou "bolha turística". Neste empreendimento estava ocorrendo o envolvimento da comunidade receptora, ao passo que estava acontecendo a integração dos residentes e turistas que vivenciavam os hábitos alimentares e a cultura cuiabana, oferecendo dessa forma a oportunidade do visitante de recriar e renovar a sua identidade revelando outras pluralidades, histórias, costumes e tradições. Sob essa ótica, Pimentel (2012) demonstra que a hospitalidade vai além de receber o hóspede, como também deve proporcionar o compartilhamento de experiências através de pessoas e culturas diferentes.

\footnotetext{
${ }^{12}$ SILVA, Jackson. Entrevista de treze minutos concedida à autora, em 19 de julho de 2017 na cidade de Cuiabá.
} 


\subsection{A HOSPITALIDADE SOB A PERCEPÇÃO DOS CLIENTES}

Nas visitas realizadas ao "Chá com Bolo Cuiabano da Tia Fran" entre os anos de 2017 e 2018, observou-se a hospitalidade presente no estabelecimento. A observação foi elaborada em dois momentos distintos, pois a dinâmica de atendimento do empreendimento aconteceu de duas formas: a primeira durante a semana, em que apenas os proprietários atendiam os clientes, e a segunda nos finais de semana e feriados com o atendimento realizado por cerca de dez garçons.

Durante a semana o estabelecimento estava funcionando em dois períodos: matutino ( $7 \mathrm{~h} 00 \mathrm{~min}$ às $10 \mathrm{~h} 00 \mathrm{~min})$ e vespertino (15h00min às $18 \mathrm{~h} 00 \mathrm{~min})$. Aos finais de semana e feriados: no período matutino (06h00min às $11 \mathrm{~h} 30 \mathrm{~min})$.

Apesar de funcionar em dois períodos durante a semana, o "Chá com Bolo Cuiabano da Tia Fran", não utilizava de mão de obra terceirizada, apenas os proprietários atendiam devido o número reduzido de clientes. A recepção se fazia calorosa com os cumprimentos de "Bom dia! ou Boa tarde!", Pode entrar! Sintam-se em casa! Os clientes se direcionavam até o balcão e realizavam os seus pedidos com a "Tia Fran", posteriormente escolhiam as suas mesas nas áreas externas ou internas para saborearem os seus bolos e salgados. Os chás e cafés estavam dispostos gratuitamente para os clientes. As conversas e os "causos" ficavam sob a reponsabilidade de Jackson Silva, um típico cuiabano que vivenciava desde a infância os costumes da cultura cuiabana. O proprietário se aproximava das mesas dos clientes cumprimentando-os e perguntava sobre a qualidade dos alimentos, bem como indagava sobre o cotidiano de Cuiabá. A maioria dos clientes estava sendo de "velhos conhecidos" e outros foram se tornando amigos por meio da convivência diária no estabelecimento.

Notou-se que a prestação de serviços do empreendimento também abarcava todo o ambiente, conforme Maria de Lourdes Barbosa et al. (2011) que demonstrava o lugar, a arquitetura, o cenário, os outros consumidores e os prestadores diretos do serviço. Esses elementos estavam colaborando para criar uma atmosfera positiva ou negativa, como em alguns casos memoráveis. A relação de proximidade com os clientes tornava o espaço do "Chá com Bolo da Tia Fran” mais acolhedor e íntimo, assim todo o ambiente dialogava com a satisfação dos consumidores, que foi explorada com a análise dos questionários. 
Os garçons que atendiam durante os finais de semana e feriados, demonstravam sentimento de familiaridade, pois em sua maioria eram conhecidos dos proprietários. Os funcionários não esboçavam cerimônia e formalismo no atendimento, mas cumpriam com rigor os serviços de alimentos e bebidas.

A tranquilidade do ambiente durante a semana possibilitava aos clientes passarem mais tempo nas mesas, mesmo com o encerramento das contas, estes ainda passavam o tempo conversando com os proprietários. Entretanto, nos finais de semana e feriados o espaço ficava extremamente lotado, tendo grande rotatividade de pessoas e pressão pelos próprios clientes em deixarem logo o espaço para que outras pessoas pudessem se acomodar. Essa situação foi visualizada durante o Dia das Mães, em que diversas famílias foram saborear o café da manhã no estabelecimento.

Em relação aos questionários semiabertos aplicados aos clientes, sobre o que entendiam por hospitalidade, estes poderiam escolher 12 termos, dentre eles: receber bem (4), atenção (2), ambiente familiar (3), bom atendimento (2), acolhedor (2) e se sentir em casa (2). Dentre as palavras escolhidas, percebeu-se que os entrevistados caracterizavam o estabelecimento como um espaço íntimo, onde se sentiam bem tanto pelo ambiente físico como pelas relações interpessoais. Essa percepção está ligada ao conceito de hospitalidade tecido por Sueli Maria Stoll (2006, p. 26-27) sendo este:

[...] o conjunto de atitudes e reações humanas, de um relacionamento assimétrico entre quem acolhe e quem é acolhido, por intervenção da informação e comunicação dirigida, tem como propósito estabelecer, manter, promover, orientar e estimular um vínculo recíproco e solidário.

Nos 10 questionários aplicados, todos os clientes assinalaram como respostas positivas, o ambiente do "Chá com Bolo da Tia Fran" como hospitaleiro, a decoração contribuiu para uma atmosfera hospitaleira, os alimentos servidos fazem parte da culinária cuiabana, o "Chá com Bolo da Tia Fran” pode ser considerado um atrativo turístico, a decoração atrai turistas, a atmosfera contribui no consumo dos produtos e o ambiente familiar favorece o atendimento acolhedor. Entretanto, entre os 10 questionários, observou-se que 2 clientes negaram que a música regional transformava o ambiente em um espaço acolhedor ou hospitaleiro.

Diante dos dados acima, verificou-se o estabelecimento "Chá com Bolo da Tia Fran", como um lugar hospitaleiro sob a ótica da experiência aguçada pela percepção 
dos sentidos, conforme Campos (2008). A autora afirma que "os cinco sentidos associados à hospitalidade fazem com que aqueles se tornem tão complexos quanto esta, graças ao caráter visivelmente extraordinário e individual da percepção sensorial ao distinguir sensações, atitudes, gostos, situações, locais e odores como agradáveis ou não" (CAMPOS, 2008, p. 14). Os cinco sentidos se unem aos sentimentos e percepções dos indivíduos que se deparam com o novo ou diferente, sendo o ambiente analisado como hospitaleiro ou hostil de acordo com os seus valores culturais.

Citam-se alguns trechos das respostas sobre os cheiros exalados pelo estabelecimento: "Lembrança de quando morava com os meus pais e a minha mãe fazia bolo de arroz". Outro cliente relatou que: "O chá de capim cidreira me faz lembrar a minha infância”. As percepções dos visitantes em relação aos cheiros presentes no "Chá com Bolo da Tia Fran", foram associadas à hospitalidade daquele ambiente que trouxe boas lembranças, de momentos memoráveis que representavam a infância dos clientes. Neste sentido, Campos (2008, p. 12) demonstra que "os odores têm o poder de evocar lembranças vívidas, carregadas emocionalmente, de eventos e cenas passadas. Se essas lembranças forem boas, ao associar-se com determinado odor, pode ser criada uma espécie de código que indica os elementos positivos da hospitalidade".

Constatou-se a hospitalidade presente no "Chá com bolo da Tia Fran", por meio dos trechos dos relatos dos clientes e por considerarem de forma unânime o ambiente como hospitaleiro, conforme o Quadro 1 a seguir:

QUADRO 1 - PERCEPÇÃO DOS CLIENTES SOBRE A HOSPITALIDADE

\begin{tabular}{|c|l|}
\hline Ambiente hospitaleiro & \multicolumn{1}{c|}{ Justificativa } \\
\hline Sim & $\begin{array}{l}\text { É o bem receber através da afetividade. Como se estivesse em um quintal } \\
\text { cuiabano. }\end{array}$ \\
\hline Sim & $\begin{array}{l}\text { Um ambiente acolhedor, com características familiares. De um ambiente } \\
\text { regional. }\end{array}$ \\
\hline Sim & $\begin{array}{l}\text { É a maneira atenciosa e agradável que uma pessoa é recepcionada em um } \\
\text { determinado local. Que me faz sentir de fato cuiabano. }\end{array}$ \\
\hline Sim & Pela simpatia e bom atendimento. O local traz tranquilidade. \\
\hline Sim & Pelo atendimento e comodidade. Sensação de estar em uma casa regional. \\
\hline Sim & $\begin{array}{l}\text { Uma ótima recepção no ambiente ao qual convivo com demais pessoas. } \\
\text { Resgate das raízes cuiabanas. }\end{array}$ \\
\hline Sim & $\begin{array}{l}\text { É o receber bem, dar atenção. A sensação de estar na casa de minha vó na } \\
\text { época da infância. }\end{array}$ \\
\hline Sim & Receber bem, se sentir como se estivesse em sua casa. \\
\hline Sim & $\begin{array}{l}\text { É o atender como alguém da família. Receber bem. Como se estivesse em } \\
\text { um quintal cuiabano. }\end{array}$ \\
\hline Sim & Alegre. \\
\hline FONTE: Pesquirat
\end{tabular}

FONTE: Pesquisa de campo, 2018. 
Verificou-se por meio das respostas dos frequentadores, a hospitalidade cuiabana presente no estabelecimento comercial "Chá com Bolo da Tia Fran", pois estes associaram o atendimento, a decoração e o ambiente como hospitaleiro e representante da cultura cuiabana. Os clientes manifestaram a satisfação pelo atendimento e espaço acolhedor, até mesmo nos finais de semana e feriados.

Os frequentadores ainda mencionaram o estabelecimento como hospitaleiro por meio da recepção, prestação de serviços e atmosfera. Estes resultados dialogam com os estudos de Campos (2008) em relação aos cinco sentidos e a hospitalidade, pois a decoração remete a moradia das famílias cuiabanas, assim a atmosfera criada para a comercialização de produtos regionais, bem como a prestação de serviços auxiliam na percepção dos clientes em relação à hospitalidade não apenas em um espaço, mas nas interações culturais, sociais e educacionais compreendidas por estes ao ver, ouvir e sentir.

\section{CONSIDERAÇÕES FINAIS}

Nesta pesquisa se investigou como a hospitalidade cuiabana se apresentava no estabelecimento "Chá com Bolo Cuiabano da Tia Fran”, na cidade de Cuiabá, no estado de Mato Grosso (Brasil). A escolha do empreendimento foi considerada apropriada para fortalecer o estudo sobre hospitalidade e a sua relação com a cultura cuiabana.

É inegável que a hospitalidade carrega em si a essência do turismo, tendo fundamental importância para fomentar o desenvolvimento turístico de determinado destino. $\mathrm{O}$ ato de bem receber integra diversas culturas e proporciona a troca de valores entre visitados e visitantes.

A pesquisa de campo trouxe resultados para a compreensão da hospitalidade cuiabana como um atrativo turístico, pois a sua gastronomia e produção de qualidade reforçaram a proposta do "Chá com Bolo da Tia Fran" como uma culinária caseira cuiabana.

A atmosfera criada para atender o público que estava frequentando o "Chá com Bolo Cuiabano da Tia Fran" estava sendo acolhedora e incitava nos clientes o desejo de 
consumir os seus produtos devido a sua organização e apresentação, bem como a sensação de saborear e experimentar os hábitos alimentares da cultura cuiabana.

A decoração do estabelecimento "Chá com Bolo Cuiabano da Tia Fran" também estava contribuindo para a percepção de qualidade que os visitantes concebiam em relação aos produtos comercializados, pois ao investir na apresentação de um layout que expressava os elementos da cultura e identidade cuiabana, os proprietários eram favorecidos pelo crescimento das vendas. Além disso, a comercialização de pratos típicos tornava os seus gêneros competitivos no setor turístico.

Os visitantes que adentravam o "Chá com Bolo Cuiabano da Tia Fran” podiam ter os seus cinco sentidos aguçados pela hospitalidade recebida naquele espaço, pois a visão, a audição, o olfato, o tato e principalmente o paladar foram tomados pela experiência de vivenciar os hábitos e costumes de Cuiabá através da sua decoração, sons, cheiros e sabores percebidos no ambiente.

O "Chá com Bolo Cuiabano da Tia Fran" estava sendo responsável pela propagação da hospitalidade cuiabana, devido às diversas experiências e sensações que os seus visitantes vivenciavam ao conhecer um lugar cercado pela cultura, história e identidade de Cuiabá.

Os resultados obtidos propiciaram a percepção sobre a constituição do objeto de estudo, a compreensão da importância e significado da hospitalidade no empreendimento sob a visão dos proprietários e clientes. As relações interpessoais no "Chá com Bolo Cuiabano da Tia Fran" foram colaboradoras para o emprego da hospitalidade cuiabana em todos os aspectos observados.

\section{REFERÊNCIAS}

BARBOSA, M. L. A; SOUZA, A. G; KOVACS, M. H; MELO, L. S. A. Gestão da experiência de serviços de hospitalidade: o que a empresa propõe e qual o significado para o consumidor. Observatório de Inovação do Turismo, v. VI, n. 2, Rio de Janeiro, Jun. 2011.

BARRETTO, M. Turismo e legado cultural. São Paulo: Papirus, 2000.

BOER, L; M. REJOWSKI. Dimensões da hospitalidade em um restaurante comercial. Turismo \& Sociedade. Curitiba, v. 9, n. 1, p. 1-23, jan. abr., 2016. 
BRASIL. Ministério do Turismo. Turismo de Saúde: orientações básicas. Brasília: Ministério do Turismo, 2010.

CALDEIRA, J. C. Delícias no Chá com Bolo Cuiabano Tia Fran/MT, dez. 2014. Disponível em: <http://www.destemperados.com.br/experiencias/delicias-no-cha-combolo-cuiabano-tia-fran >. Acesso em: 03/07/2017.

CAMARACBA. Centro Geodésico da América do Sul, s.d. Disponível em: $<$ http://www.camaracba.mt.gov.br/index.php?pag=tur_item\&id=2>. Acesso em: 26/12/2018.

CAMARGO, L. O. L. Os interstícios da hospitalidade. Revista Hospitalidade. São Paulo, v. XII, n. especial, p. 42-69, mai. 2015.

CAMPOS, S. R. Os cinco sentidos da hospitalidade. Observatório de Inovação do Turismo, Rio de Janeiro, v. 3, n. 1, mar. 2008.

CASCUDO, L. C. História da alimentação no Brasil: cardápio indígena, dieta africana, ementa portuguesa. São Paulo: Companhia Editora Nacional, 1967.

FREYRE, G. Açúcar: uma sociologia do doce, com receitas de bolos e doces do Nordeste do Brasil. São Paulo: Editora Global, 2007.

GIL, A. C. Como elaborar projetos de pesquisas. São Paulo: Atlas, 2008.

G1 MT. Lei declara o bolo de arroz cuiabano como prato típico de Mato Grosso, 2017. Disponível em: <http://g1.globo.com/mato-grosso/noticia/2017/01/lei-declara-obolo-de-arroz-cuiabano-como-prato-tipico-de-mato-grosso.html >. Acesso em: 10/07/2017.

IGNARRA, L. R. Fundamentos do Turismo. São Paulo: Thomson, 2003.

IPDU. Perfil socioeconômico de Cuiabá: v. IV. Cuiabá: Central de Textos, 2010.

MANCUSO, M. I. R; CALDEIRA, R; SILVA, S. R. L. Saber e sabor na Fronteira do Mato Grosso: o bolo de arroz. In: XXXI Congresso Alas Uruguay, Montevidéu, 3-8 dez. 2017. Anais eletrônicos. Disponível em: <http://alas2017.easyplanners.info/opc/t1/8026_mancuso_maria_ines_rauter.pdf $>$. Acesso em: 20/12/2017.

MARUJO, N. O estudo de caso na pesquisa em turismo: uma abordagem metodológica. Turismo: Estudos \& Práticas (RTEP/UERN), Mossoró/RN, v. 5, n. 1, jan./jun. 2016.

MATIAS, M. Organização de eventos: procedimentos e técnicas. Barueri: Manole, 2001.

PIMENTEL, R. F. D. A hospitalidade brasileira no mercado turístico internacional. Observatório de Inovação do Turismo, Rio de Janeiro, v. 2, n. 2, abr. 2012. 
PORTAL MATO GROSSO. O Rasqueado Cuiabano. Disponível em: $<$ http://www.portalmatogrosso.com.br/imprime.php?cid=16950\&sid=358 >. Acesso em: $18 / 07 / 2017$.

REGO, R. A.; SILVA, E. A. A atmosfera das cidades e a hospitalidade. In: DENCKER, A. de F. M; BUENO, M. S. (orgs.). Hospitalidade: Cenários e oportunidades. São Paulo: Editora Thomson, 2003.

SILVA, E. A. Atmosfera de loja de varejo: um estudo exploratório sobre as interfaces entre marketing e arquitetura visando influenciar o comportamento do consumidor. Dissertação (Mestrado em Administração). Londrina: UNOPAR, 2001.

STOLL, S. M. Hospitalidade: conceitos e reflexões sobre sua percepção prática dentre os hoteleiros do destino turístico Balneário Camboriú - SC. Dissertação (Mestrado em Turismo e Hotelaria). Balneário Camboriú: UNIVALI, 2006.

TADINI, R. F; MELQUIADES, T. Fundamentos do Turismo. Rio de Janeiro: Fundação CECIERJ, 2010.

\section{ENTREVISTA}

SILVA, Jackson. Entrevista de treze minutos concedida à autora, em 19 de julho de 2017 na cidade de Cuiabá.

Recebido em: 20-06-2018.

Aprovado em: 20-07-2018.

Versão finalizada para publicação em: 21-01-2019. 